OPEN ACCESS

Edited by: Urs Schmidhalter, Technical University of Munich,

Germany

Reviewed by:

Pablo J. Zarco-Tejada, The University of Melbourne, Australia Martin Gnyp, Yara International (Germany), Germany

*Correspondence: Josephine Bukowiecki bukowiecki@pflanzenbau.uni-kiel.de

Specialty section: This article was submitted to Technical Advances in Plant Science, a section of the journal Frontiers in Plant Science

Received: 29 March 2019 Accepted: 23 December 2019 Published: 14 February 2020

Citation:

Bukowiecki J, Rose T, Ehlers $R$ and Kage H (2020) High-Throughput Prediction of Whole Season Green Area Index in Winter Wheat With an Airborne Multispectral Sensor.

Front. Plant Sci. 10:1798. doi: 10.3389/fpls.2019.01798

\section{High-Throughput Prediction of Whole Season Green Area Index in Winter Wheat With an Airborne Multispectral Sensor}

\author{
Josephine Bukowiecki ${ }^{*}$, Till Rose, Ralph Ehlers and Henning Kage \\ Institute of Crop Science and Plant Breeding, Christian-Albrechts-University, Kiel, Germany
}

Introduction: In recent decades, the interest has grown to quantify the green area index as one of the key characteristics of crop canopies (e.g. for modelling transpiration, light interception, growth). The approach of estimating green area index based on multispectral reflection data from unmanned airborne vehicles with lightweight sensors might have the potential to deliver data with sufficient accuracy and high throughput during the whole season.

Materials and Methods: We therefore examined the applicability of a recently launched drone-based multispectral system (Sequoia, Parrot) for the prediction of whole season green area index in winter wheat, with data from field trials in Northern Germany (2017, 2018 and 2019). The explanatory power of different modeling approaches to predict green area index based on multispectral data was tested: linear and non-linear regression models, multivariate techniques, and machine learning algorithms. Further, different predictors were implemented in these models: multispectral data as raw bands and as ratios. Additionally, a new approach for the evaluation of green area index predictions during senescence is introduced. It is shown that a robust calibration during growth phase is applicable during senescence as well.

Results and Discussion: A linear model which includes all four wavebands provided by the sensor in three ratios (VIQUO) and a Support Vector Machine (SVM) algorithm allow a reliable and sufficiently accurate whole season prediction. The VIQUO-model is recommended as the best model, as it is precise but still relatively simple, thus easier to communicate and to apply than the SVM. The integrated values of predicted green area indices in an independent trial are highly correlated with their final biomass $\left(R^{2}\right.$ : VIQUO $=0.84$, SVM $\left.=0.85\right)$ which represents the process of radiation interception, one of the determining factors of growths. This is an indicator for both, a robust model calibration and a high potential of the tested multispectral system for agricultural research and crop management.

Keywords: green area index, unmanned aerial vehicle, multispectral, winter wheat, whole season, vegetation index, sequoia camera 


\section{INTRODUCTION}

In agricultural science, the monitoring of canopies throughout the growing season is of major concern to understand, predict, and manage crop growth. A fundamental parameter of canopies is the green area index (green plant area per ground area; GAI), which plays a central role in the processes of radiation interception and transpiration by vegetation. Because GAI changes continuously from sowing to harvest, sequenced measurements are necessary. For this purpose, non-destructive methods are advantageous. Additionally, applications in precision agriculture and the phenotyping of large plant material collections require the measurement of large areas in feasible time. Both demands are fulfilled by remote spectral sensors (Salamí et al., 2014).

Since the first introduction of remote sensing data for the satellite driven surveillance of vegetated areas, this field of research has developed significantly (Weiss et al., 2020). In the same time, new scopes of application of spatial data have emerged. It became quickly evident that satellite sensors cannot meet all requirements of remote sensing applications, due to insufficient spatial and temporal resolution. To overcome these restrictions, new platforms for complemental or alternative data acquisition were introduced (e.g. onboard traction-engine, airplanes) (Zecha et al., 2013).

First developed for military applications (Majumdar et al., 2001; Beard et al., 2006), unmanned aerial vehicles (UAV) turned in focus of civilian remote sensing with special attention in the domain of agriculture (Salamí et al., 2014). With their measurement distance between ground (tractor, handheld) and satellite, UAV can reach both, high ground coverage as well as high spatial resolution. Furthermore, they are independent of cloud cover (in contrast to satellites) and are in some environments the only opportunity to reach sufficient temporal resolution within certain time periods during season. Considering these features, UAVs might be the most promising carrier systems for airborne spectral sensors in agricultural research and precision agriculture (Puri et al., 2017; Raparelli and Bajocco, 2019; Tsouros et al., 2019).

Despite the high spatial resolution of UAV-data, there are still a lot of factors influencing the spectral reflectance signal, such as soil background and radiation conditions. To compensate this spectral variability, it is common practice to associate crop characteristics not only with one spectral band, but with at least two, merged into a vegetation index (VI) (Tucker et al., 1981; Baret and Guyot, 1991; Verger et al., 2014).

In recent decades, a high number of VIs have been developed to characterize different crop characteristics. The certainly most popular VI is the normalized difference vegetation index (NDVI) by Rouse et al. (1974), combining the spectral range of red with the near infrared (NIR). The NDVI has been shown to be sensitive to different crop characteristics, such as leaf area index (LAI), GAI, dry matter, and nitrogen content (e.g. Serrano et al., 2000; Lelong et al., 2008; Berni et al., 2009; Mistele and Schmidhalter, 2010; Nebiker et al., 2016; Ni et al., 2017).
However, it is a known fact that the sensitivity of the NDVI towards these crop characteristics is heavily dependent on the degree of soil coverage, being insensitive above a $L A I$ of 2-3 $\mathrm{m}^{2} \mathrm{~m}^{-2}$ (Serrano et al., 2000; Haboudane et al., 2004; Pinty et al., 2009; Viña et al., 2011). Thus, for the most crops the NDVI cannot provide information for a long time in the vegetation period. Several newly developed VIs are more or less able to compensate this saturation effect, but are still subject to a number of influences restricting their usability through the whole growing season and on different sites, such as different species, growth stages, the process of senescence, site- and year-effects (e.g. Gitelson et al., 2003; Serrano et al., 2000; Li et al., 2010).

In recent time, new, multivariate methods as well as nonlinear algorithms have been introduced in the calibration of spectral data to crop data, such as Partial Least Squares Regression (Höskuldsson, 1988) or Support Vector Machines (SVM) (Burges, 1998). As a consequence of this broad field of different VIs, used spectral bands, different multispectral sensors, and different prediction models, the best way to use a spectral sensor for the prediction of any canopy characteristic might be reassessed separately for each new sensor model.

Therefore, the objective of this study was to develop an easyto-handle, reliable UAV-based approach to predict whole season GAI of winter wheat which could usefully be transferred into precision agriculture and support agricultural research. For this purpose, a recently launched low to medium cost UAV-based multispectral system was deployed, namely the Parrot Sequoia sensor.

The focus was on the questions: (1) Is the Sequoia sensor providing sufficiently meaningful multispectral images for the monitoring of winter wheat growth on plot level? (2) How can the data be used best for the prediction of the crop characteristic GAI? (2a) Can one calibration approach for GAI be employed throughout the whole growing season? (2b) Are the VI-based approaches excelled by the new multivariate methods?

\section{MATERIALS AND METHODS}

\section{Study Site and Trial Design}

Data acquisition was conducted during three years (growing seasons 2016/17, 2017/18 and 2018/19) at the Hohenschulen Experimental Farm (10.0 E, $54.3 \mathrm{~N}, 30 \mathrm{~m}$ a.s.l.) of the Kiel University, located in Northern Germany. The long-term average temperature is $8.9^{\circ} \mathrm{C}$, the precipitation average $788 \mathrm{~mm}$ (Deutscher Wetterdienst, 2013). The site is characterized by a small-scale heterogeneous soil, the main soil type being a pseudogleyic sandy loam.

Destructive sampling for sensor calibration was conducted as additional measurement in different ongoing trials. In the growing season 2016/17, data were collected within Trial A and Trial B, in 2017/18 in Trial B and Trial C and in 2018/19 only in Trial C. Trial A is a four-field rotation since 2003, with winter wheat following winter oilseed rape. Four different nitrogen levels are tested in 
interaction with four different cultivars in four replications (Table 1). Trial B and C are experimental sites, placed each year on a different field. In Trial B four different sowing densities of four cultivars are examined whereas in Trial $\mathrm{C}$ six cultivars and two nitrogen levels are tested (Table 1). Except the treatments mentioned, the wheat crops were managed according to regional farmer's practice.

\section{Data Collection}

The following sections (GAI Reference Measurement up to Advanced Predictive Models) describe the process from data

TABLE 1 | Different treatments of the three field trials.

\begin{tabular}{|c|c|c|c|}
\hline \multirow{2}{*}{$\begin{array}{l}\text { Trial } \\
\text { (Replications) }\end{array}$} & \multicolumn{3}{|c|}{ Treatments } \\
\hline & Cultivar & $\begin{array}{l}\text { Nitrogen levels and split } \\
\text { application rates } \\
{\left[\mathrm{kg} \mathrm{N} \mathrm{ha}^{-1}\right]}\end{array}$ & $\begin{array}{l}\text { Sowing Seed } \\
\text { Density } \\
\text { [Kernels } \mathrm{m}^{-2} \text { ] }\end{array}$ \\
\hline $\begin{array}{l}\text { Trial A } \\
(\mathrm{n}=3)\end{array}$ & $\begin{array}{l}\text { Benchmark } \\
\text { Dekan } \\
\text { KWS } \\
\text { Maddox } \\
\text { RGT } \\
\text { Reform }\end{array}$ & $\begin{array}{c}\text { 0: } 0 / 0 / 0 \\
\text { 80: 40/40/0 } \\
\text { 160: 80/40/40 } \\
\text { 240: } 80 / 80 / 80\end{array}$ & 270 \\
\hline $\begin{array}{l}\text { Trial B } \\
(n=3)\end{array}$ & $\begin{array}{l}\text { Brilliant } \\
\text { Dekan } \\
\text { Piko } \\
\text { Solehio }\end{array}$ & 200: 80/80/60 & $\begin{array}{c}50 \\
100 \\
200 \\
400\end{array}$ \\
\hline $\begin{array}{l}\text { Trial C } \\
(n=4)\end{array}$ & $\begin{array}{l}\text { Elixer } \\
\text { Hybery } \\
\text { JB Asano } \\
\text { Piko } \\
\text { SUR99820 } \\
\text { Solehio }\end{array}$ & $\begin{array}{c}\text { 110: 50/60/0 } \\
\text { 220: 50/110/60 }\end{array}$ & 280 \\
\hline
\end{tabular}

collection through data processing to model calibration and evaluation. To clarify the procedure, it is illustrated schematically in Figure 1.

\section{GAl Reference Measurement}

At every sampling date (Table 2), three replications of the respective trial were sampled, hence 48 plots. In every plot, the aboveground plant material of an area of $0.25 \mathrm{~m}^{2}$ was withdrawn and its BBCH stage (Lancashire et al., 1991) was scored. The fresh matter was fractionized into leaf, stem, ear, and senescence. The category senescence comprised all fresh matter no longer considered as green and was the only fraction not being included in the calculation of the GAI, wherefore the LAI, Stem Area Index and Ear Area Index were determined using a LiCor 3100 leaf area meter (LiCor Inc., NE, USA).

TABLE 2 | Sampling dates and the most frequent BBCH stage (mode).

\begin{tabular}{lccc} 
Trial & \multicolumn{3}{c}{ Sampling date (BBCH) } \\
\cline { 2 - 4 } & Season 2016/17 & Season 2017/18 & Season 2018/19 \\
\hline Trial A & $2017-04-11(31)$ & - & - \\
& $2017-05-16(37)$ & & \\
& $2017-06-07(65)$ & & \\
& $2017-06-27(75)$ & & - \\
& $2017-08-07(92)$ & & \\
Trial B & $2017-08-29(0)$ & & \\
& $2017-04-04(30)$ & $2018-03-14(21)$ & \\
& $2017-05-09(33)$ & $2018-04-24(29)$ & \\
& $2017-05-30(51)$ & $2018-05-22(37)$ & \\
& $2017-07-18(83)$ & &
\end{tabular}

Trial C

2018-04-18 (24)

2018-11-27 (21) 2018-05-15 (37) 2018-06-04 (61) 2019-04-09 (31) 2018-07-17 (92)

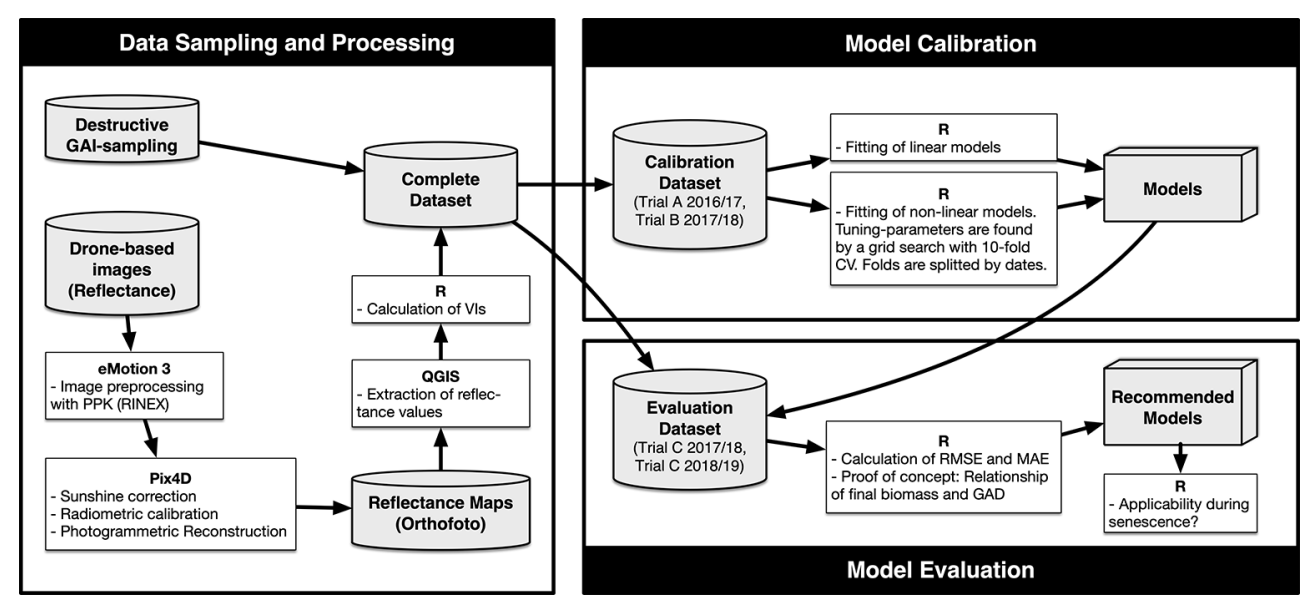

FIGURE 1 | Flowchart of the process of data collection, data processing, model calibration, and model evaluation (CV, cross validation; GAD, green area duration; MAE, mean absolute error; RMSE, root mean square error; VI, vegetation index). 
On August 07, 2017 and on July 17, 2018 ripening was considered as terminated $(\mathrm{BBCH} 92)$, thus, at these dates a GAI of 0 was assigned to each plot of the relevant trial. Spectral data from the bare ground of the plots from Trial A at August 29, 2017 were included in the dataset as well.

A description of the GAI-course during the senescence by destructive sampling and measurements of the green area is not possible as the differentiation between green and senesced plant material is not clearly defined and because, in parallel to this zonal process, a gradual degradation of chlorophyll takes place. The concept to evaluate GAI-predictions during this development stage is further specified in Further Evaluation of GAI-Models.

\section{Reflectance Measurements}

Every sampling date was accompanied by an overflight with an UAV-based multispectral camera within at most three days. The plant development during this time span was considered as negligible, thus no interpolation techniques (as for example used by Broge and Mortensen, 2002) were applied. An overflight after the sampling was in each case used to know at which position the samples were taken exactly, by visual determination of the additional hole in the canopy. For further evaluation of the GAI-models, 14 additional overflights on Trial C in the season 2017/18 were made (April 04, April 16, April 23, May 03, May 16, May 22, June 01, June 06, June 12, June 20, June 26, July 05, July 13, July 17 ).

The UAV applied was an eBee by senseFly, a micro aerial vehicle (following the classification of Allen et al., 2011), with fixed wings and automatic flight manager. It served as carrier system for the Parrot Sequoia camera (Parrot Drones SAS, France, Paris), a multispectral sensor which records simultaneously images in four reflection-bands; green $(550 \mathrm{~nm})$, red $(660 \mathrm{~nm})$, red edge (RE, $735 \mathrm{~nm}$ ), and near-infrared (NIR, $790 \mathrm{~nm}$ ). Besides RE, all reflection-bands have a bandwidth of $40 \mathrm{~nm}$, RE just of $10 \mathrm{~nm}$. The Sequoia camera has an incoming light sensor and provides therefore fractional reflection values regarding the incoming radiation. Before each flight, images of a grayscale target were made for radiometric calibration.

The software eMotion3 from senseFly was used as flight manager. Every position on the ground was at least photographed five times to ensure a sufficient data quality. The chosen resolution was $8 \times 8 \mathrm{~cm} \mathrm{pixel}^{-1}$. All images were preprocessed in the post flight-manager of eMotion 3 and afterwards imported and processed using the Pix4Dmapper software (Pix4D SA., Switzerland). On days with fast moving clouds, a manual screening of the images was conducted to exclude those images containing both, regions with cloud shadow and full sunlight. The results were four orthogonal reflection maps, one for every waveband. The extraction of the reflectance data of the sampling spots was undertaken in QGIS version 3.8.0 (QGIS Development Team, 2018), whereby all pixels of a sampling spot were summarized as median.

With a RTK-enabled eBee, it is possible to include RINEXfiles (Receiver Independent Exchange Format) in the post-flight- processing in eMotion 3. If this function was not available, the reflectance maps were georeferenced manually using the Georeferencer Plugin in QGIS.

\section{MODEL CALIBRATION}

\section{Data Sets}

At the very beginning, plots assessed as compromised in any manner (e.g. strong weed abundance, damages by game, lodging) were excluded of further consideration. This affected especially Trial B, as in 2017 the data of the whole sowing density $50 \mathrm{~K} \mathrm{~m}^{-2}$ treatment were sorted out due to strong weed abundance and the data of sowing density $400 \mathrm{~K} \mathrm{~m}^{-2}$ of the cultivar Solehio after early July due to lodging. In 2018 in Trial B, problems in crop establishment of the cultivar Dekan and additional waterlogging stress led to too little sampling material in the lowest sowing density variant at the end of May and in the two lowest sowing density variants in June.

Considering GAI, values above $7 \mathrm{~m}^{2} \mathrm{~m}^{-2}$ were excluded from the dataset because under local growing conditions these high values do never occur as a treatment mean and they were considered as more harmful then useful for calibration purposes (concerns six samples of the calibration dataset and one of the evaluation dataset). Furthermore July 18, 2017; June 27, 2017 and June 11, 2018 were omitted from GAIdataset as the process of senescence had already started (see GAI Reference Measurement).

Finally, the data from Trial A and Trial B (2016/17 and 2017/18) were combined to form one single calibration dataset, covering a broad spectrum of $G A I$-values, crop managements, and environmental factors (e.g. irradiance at flight day, ground coverage, nitrogen levels and sowing densities), whereas the data from Trial C constitute the evaluation dataset ( $45 \%$ of the total data volume). Calibration and evaluation dataset never share a common date and flight, respectively. The result is a high level of independence between both data sets (final sample size for GAIcalibration: 474, GAI-evaluation: 383 ).

\section{Statistical Analysis}

All statistical analysis was conducted in R Core Team, 2017.

\section{Linear Regression Models}

Every single band, their combination with and without interaction, the quotients of NIR and Green, NIR and Red, NIR and RE, their combination with and without interaction and the NDVI (the quotient of NIR-Red and NIR+Red, by Rouse et al., 1974), as most common VI, were tested for their sensitivity towards GAI.

Based on the calibration dataset, linear models between GAI and the components of the VIs were fitted, whereas for the NDVI an exponential term was introduced, taking into consideration its known non-linear behavior (Wiegand et al., 1992; Chen and Cihlar, 1996; Myneni et al., 1997; Lelong et al., 2008; Viña et al., 2011). 
For the comparison of the different VIs, two statistical metrics were selected: the root mean square error (RMSE) and the mean absolute error (MAE). The RMSE was chosen for comparability with the results of other studies. However, since the RMSE gives more weight to large errors but the predictive power of the models at low GAI-values is at least as important as at high GAIvalues (non-linear relationship between light interception and $G A I)$, the MAE was used to compare the advantages and disadvantages of the different models.

\section{Advanced Predictive Models}

To streamline the process of model creation, the integrative package caret (Kuhn, 2017) was used. The models were implemented by different additional packages: Partial Least Squares Regressions using pls (Mevik et al., 2016), SVM using kernlab (Karatzoglou et al., 2004), K Nearest Neighbor using caret (Kuhn, 2017), Multivariate Adaptive Regression Spline using earth (Milborrow, 2017), and Boosted Trees using $\mathrm{gbm}$ (Ridgeway, 2017).

For Partial Least Squares, SVM, and K Nearest Neighbor, all predictors were centered and scaled prior to model fitting. The models Partial Least Squares, SVM, K Nearest Neighbor, Multivariate Adaptive Regression Spline, and Boosted Trees possess tuning parameters. These were found by a grid search and the optimal model was selected by the smallest RMSE value. The parameters usually have a tradeoff between descriptive and predictive modeling performance. To prevent overfitting by an optimization of the descriptive quality, the RMSE for parameter selection was calculated by a 10 -fold cross-validation. The holdout sample was specifically selected by date. Tuning parameter "n.minobsinnode" for the Boosted Tree model was held constant at the value of 10 . Selected tuning parameters are shown in Table S1.

\section{Further Evaluation of GAI-Models}

To examine the sensitivity of some selected VIs through the growing season, the dataset was further divided in seven different GAI-classes and the MAE and the relative MAE (rMAE) of the $G A I$-predictions in the different $G A I$-classes was calculated individually. As the rMAE is determined as the quotient of the MAE and the mean GAI of the considered class, no rMAE could be calculated for the class "Dead Plant" (division through 0 not possible).

Further it was considered if one GAI-model can be applied regardless of the cultivar (unaffected by different leaf angles and single leaf reflectance). For this purpose, calibration and evaluation dataset were reduced to the data of the two cultivars represented in both datasets: Solehio and Piko. Those two cultivars are quite contrasting ones (Table 3): Piko represents a compact growth habitus with rather short and planophile leaves while Solehio shows a pronounced vertical growth with long, erectophile leaves. Based on the calibration subset, two linear models were calibrated; a "common" model which estimates the GAI via reflectance data only and an "extended"
TABLE 3 | Characteristics of the cultivars Piko and Solehio (May 9, 2017; sowing density $400 \mathrm{~K} \mathrm{~m}^{-2}$ ).

\begin{tabular}{lcc}
\hline Characteristic & Piko & Solehio \\
\hline Mean Angle $\left(^{\circ}\right)$ & 63.5 & 72.5 \\
Stem Dry Matter/Leaf Dry Matter & 1.21 & 2.18 \\
Specific Leaf Area $\left(\mathrm{g} \mathrm{m}^{-2}\right)$ & 185.94 & 171.95 \\
Leaf Nitrogen Concentration (\%) & 4.71 & 4.4 \\
\hline
\end{tabular}

model, including the cultivar as an additional factor. The effect of cultivars on the GAI-estimation was assessed by comparing the MAEs of the models with regard to the calibration- and the evaluation dataset. Additionally, an ANOVA was performed to test whether there is a significant difference between the two models or rather a significant effect of the cultivars in the "extended" model.

For the examination of the models during the senescence we built on the approach of Serrano et al. (2000) of introducing an empirical green fraction factor. However, in contrast to the biomass-based approach of Serrano et al. (2000), a chlorophyll-driven approach was chosen. The methodology is based on SPAD-measurements which are converted into a "canopy greenness"-factor. Required data for this approach were collected by measurements with a chlorophyll meter (SPAD-502, Konica Minolta) in the growing season 2016/17 during the phase from maximal GAI until harvest on 13 dates (June 20, June 24, June 28, July 2, July 5, July 8, July 11, July 14, July 17 , July 20 , July 23 , July 26, and July 30 ) in all leaf layers (10 leaves per layer). Used plant material was a subset of a large genotype trial (eight genotypes: Piko, Dekan, Hybery, Jafet, Biscay, SUR99820, Brilliant, and Lambriego Inia, in three replications). Crop management included $220 \mathrm{~kg} \mathrm{~N}^{-1}\left(\mathrm{~N}_{\min }\right.$ in early spring subtracted) and application of herbicides as well as pesticides. Tested plots were spread over a large area with much variation in soil properties, which resulted in an increased variation regarding the canopy greenness during senescence. Different leaf layers make up for different shares of the total canopy area. To account for this effect, 20 shoots of each genotype were sampled, fractionated into leaf layers, stem, and spike and the green area was determined as described before.

Multiple authors showed a nonlinear relationship between SPAD-measurements and chlorophyll concentrations (Markwell et al., 1995; Uddling et al., 2007; Ling et al, 2011). To get a closer link to the physiological base of "greenness", we transformed SPAD-readings to chlorophyll concentrations in $\mathrm{g} \mathrm{m}^{-2}$ (per unit leaf area), using the equation from Uddling et al. (2007).

Chlorophyll concentrations of each leaf layer were multiplied by its fraction of the overall canopy leaf area and the sum of these weighted concentrations is the average chlorophyll concentration of the canopy in $\mathrm{g} \mathrm{m}^{-2}$.

Weibull curves were fitted on single plot level to the relationship between chlorophyll concentration and thermal time. Each value of a plot was reduced by the minimum value of its fit and afterwards divided by its maximum value, resulting 
in the parameter "measured canopy greenness" (ranges between one at maximal GAI and 0 when leaves are clearly senesced.

For the evaluation of the GAI-models during the senescence, all predicted values after June 19 (start of senescence) were divided by the value on June 19 to get the "predicted canopy greenness". These predictions were hence correlated to the measured canopy greenness and the goodness of fit was assessed via MAE and $\mathrm{R}^{2}$.

In a final step, the informative value of the calibrated models was tested by their application. This had two objectives: The evaluation of the whole season GAI-predictions with the different models and the illustration of the potential and suitability of the resulting GAI-information for agricultural research and commercial crop production.

For this purpose, we refer to a very simple but common method of correlating VI-measurements with crop characteristics (Watson et al., 1963; Pinter et al., 1981; Tucker et al., 1981; Bartholome, 1988; Rasmussen, 1992; Serrano et al., 2000). In these studies the spectral measurements were summarized in a VI, most commonly the NDVI, and, either on single dates or time-integrated over multiple dates, correlated with crop yield or final biomass. In this context, the VI represents the duration and intensity of the photosynthetic capacity of the canopy (Serrano et al., 2000) and it has been proven that the correlation of the parameters can be increased by a good performing VI (Tucker et al., 1981; Serrano et al., 2000). It seems therefore suitable to test our GAI-models with this approach.

Sequoia data from the 14 flights in the season 2017/18 from Trial C was hence used to calculate GAI-courses on plot level through the whole season with the different tested GAI-models. Between the dates, the GAI was linearly interpolated. Subsequently, the green area duration was calculated by integrating the GAI over the whole season. Then, the proportion of variance explained of the final biomass was examined. Furthermore, the development of the variance explained during season was considered, hence whether and how efficient the GAI-models convert additional multispectraldata to agronomic reasonable information.

\section{RESULTS}

\section{Linear Regression Models}

None of the single bands performs convincingly $\left(\mathrm{MAE}_{\text {evaluation }}=1.41-2.64 \mathrm{~m}^{2} \mathrm{~m}^{-2}\right.$, Table S2). Combining the bands increases the performance considerably, especially if interactions between the bands are allowed (16 different terms, $\mathrm{MAE}_{\text {evaluation }}=0.99 \mathrm{~m}^{2} \mathrm{~m}^{-2}$, Table S2). The single ratio-models perform noticeably better than the single band-models $\left(\right.$ MAE $_{\text {evaluation }}=0.55-0.81 \mathrm{~m}^{2} \mathrm{~m}^{-2}$, Table 4). The combination of different ratios provides considerably better results than the single ratios, with a lower $\mathrm{MAE}_{\text {calibration }}$ if interactions are allowed, but with a better performance at evaluation if not (Table 4). It is noteworthy that the increase of the predictive error from calibration to evaluation is considerably lower for most of the Simple Ratio approaches (on average 61\%, Table 4), than for the single bandmodels (on average $80 \%$, Table S2) and that the increase of the single-band model with interaction is the highest (230\%).

In summary, the combination of NIR/Green, NIR/Red, and NIR/RE without interaction convinces the most $\left(\mathrm{MAE}_{\text {evaluation }}=0.45 \mathrm{~m}^{2} \mathrm{~m}^{-2}\right.$ and $\mathrm{RMSE}_{\text {evaluation }}=0.71 \mathrm{~m}^{2} \mathrm{~m}^{-2}$, Table 4), followed by the simple ratio of NIR/RE $\left(\mathrm{MAE}_{\text {evaluation }}=0.55 \mathrm{~m}^{2} \mathrm{~m}^{-2}\right.$ and $\mathrm{RMSE}_{\text {evaluation }}=0.74 \mathrm{~m}^{2} \mathrm{~m}^{-2}$, Table 4).

These two were hence selected for further evaluation, together with the $\mathrm{NDVI}_{\text {exp }}$ as the most common VI. The VI combining all spectral bands provided by the Sequoia camera as NIR-based quotients was named VIQUO. The equations for the calibrated models are given in Table 4.

\section{Advanced Predictive Models}

On average, the advanced predictive models perform better than the VI-models, in terms of raw reflections, reflectance ratios, in the calibration and the evaluation (Tables 4, 5, S2 and S3). While the raw data models provide similar MAEs in terms of calibration, their MAEs in the evaluation are at least $111 \%$ higher (Tables 5 and S3).

Focusing on the ratio-based models, it is noticeably that the best predictive models in calibration are the worst in the

TABLE 4 | Measurement of model performance for VI-based GAl-prediction $\left[\mathrm{m}^{2} \mathrm{~m}^{-2}\right]$ in calibration and evaluation with ratios of reflections as predictors and the equation for the calibrated GAl-models.

\begin{tabular}{|c|c|c|c|}
\hline $\begin{array}{l}\text { Linear } \\
\text { model }\end{array}$ & $\begin{array}{l}\text { MAE }_{\text {calibration }} \\
\text { (RMSE } \\
\text { calibration) }\end{array}$ & $\begin{array}{l}\text { MAE }_{\text {evaluation }} \\
\text { (RMSE } \\
\text { evaluation) }\end{array}$ & Equation \\
\hline NIR/RE & $0.44(0.60)$ & $0.55(0.74)$ & $-5.498+4.64 \cdot \mathrm{NIR} / \mathrm{RE}$ \\
\hline NIR/Red & $0.45(0.69)$ & $0.81(1.27)$ & $-0.2066+0.1984 \cdot \mathrm{NIR} / \mathrm{Red}$ \\
\hline NIR/Green & $0.36(0.56)$ & $0.64(0.98)$ & $-1.023+0.499 \cdot$ NIR/Green \\
\hline $\begin{array}{l}\text { NIR/RE + } \\
\text { NIR/Red + } \\
\text { NIR/Green } \\
\text { (VIQUO) }\end{array}$ & $0.35(0.53)$ & $0.45(0.71)$ & $-2.829243+1.814068 \cdot \mathrm{NIR} / \mathrm{RE}-0.004532 \cdot \mathrm{NIR} / \mathrm{Red}+0.321576 \cdot \mathrm{NIR} /$ Green \\
\hline $\begin{array}{l}\text { NIR/RE } \times \\
\text { NIR/Red } \times \\
\text { NIR/Green }\end{array}$ & $0.31(0.51)$ & $0.46(0.72)$ & $\begin{array}{l}0.23558-0.72441 \cdot \mathrm{NIR} / \mathrm{RE}+0.11783 \cdot \mathrm{NIR} / \text { Red }-0.02023 \cdot \mathrm{NIR} / \text { Green }+0.01313 \cdot \mathrm{NIR} / \text { Red } \cdot \mathrm{NIR} / \text { Green }+ \\
0.10864 \cdot \mathrm{NIR} / \text { Red } \cdot \mathrm{NIR} / \mathrm{RE}+0.28252 \cdot \mathrm{NIR} / \mathrm{RE} \cdot \mathrm{NIR} / \text { Green }-0.01195 \cdot \mathrm{NIR} / \mathrm{RE} \cdot \mathrm{NIR} / \text { Green } \cdot \mathrm{NIR} / \text { Red }\end{array}$ \\
\hline$N D V I_{\exp }$ & $0.42(0.66)$ & $0.69(1.04)$ & $0.00197 \cdot \exp (8.42847 \cdot((\mathrm{NIR}-\mathrm{Red}) /(\mathrm{NIR}+\mathrm{Red}))$ \\
\hline mean & $0.39(0.59)$ & $0.58(0.89)$ & \\
\hline
\end{tabular}

MAES are colored dark grey if they are higher than the mean and white if equal or lower. 
TABLE 5 | Measurement of model performance for GAl-prediction $\left[\mathrm{m}^{2} \mathrm{~m}^{-2}\right]$ with advanced predictive models in calibration and evaluation with ratios of reflections as predictors.

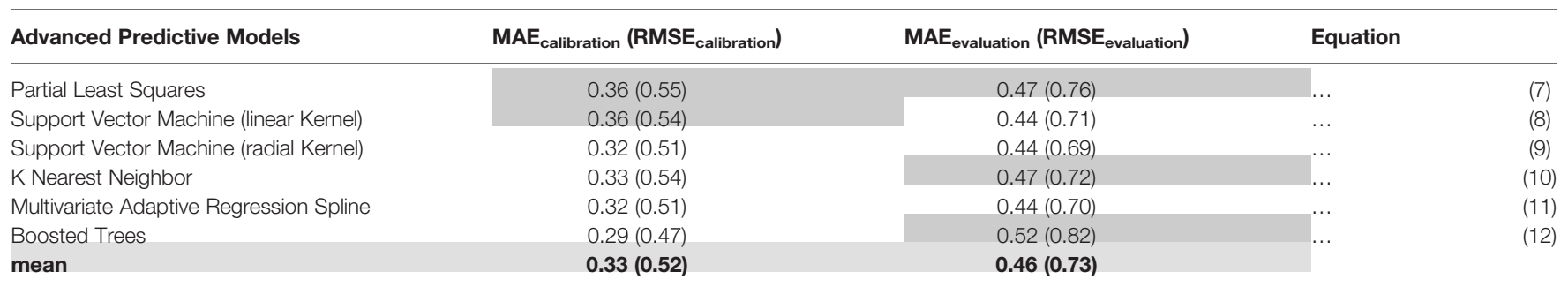

MAEs are colored dark grey if they are higher than the mean and white if equal or lower.

evaluation (e.g. Boosted Trees with an increase of predictive error of 79\%, Table 5). The best models in the evaluation are the SVMs with linear respectively radial Kernel and the Multivariate Adaptive Regression Spline $\left(\mathrm{MAE}_{\text {evaluation }}=0.44 \mathrm{~m}^{2} \mathrm{~m}^{-2}\right)$. Due to its relative simplicity, the SVM with linear Kernel (SVM, $\mathrm{MAE}_{\text {evaluation }}=0.44 \mathrm{~m}^{2} \mathrm{~m}^{-2}$ and $\left.\mathrm{RMSE}_{\text {evaluation }}=0.71 \mathrm{~m} \mathrm{~m}^{-2}\right)$ is chosen to represent advanced predictive modeling methods for further investigation and comparison with the VI-models.

\section{Further Evaluation of GAI-Models}

Comparing the performance of the selected VI-models with the SVM via their MAEs (Tables 4 and 5), it can be stated that the SVM performs considerably better than the $\mathrm{NDVI}_{\text {exp }}$ and the NIR/RE, both in terms of calibration and evaluation, whether the VIQUO has a lower $\mathrm{MAE}_{\text {calibration }}$ as the SVM and its $\mathrm{MAE}_{\text {evaluation }}$ is only slightly higher. The increase of predictive error from calibration to evaluation is relatively high with the $\mathrm{NDVI}_{\exp }$-model $(64 \%$, Table 4), but nearly the same with the SVM-, the NIR/RE- and the VIQUO-model (22-29\%, Tables 4 and 5). However, while the predictive error of SVM and VIQUO is increasing at high GAIvalues, the predictions of NIR/RE meets the high GAIs well, but its predictions at low $G A I$-values scatter strongly, producing for the most part negative predictions (Figure 2). Looking at Figure 2, it is notably that several points in the high GAI-range in the evaluation

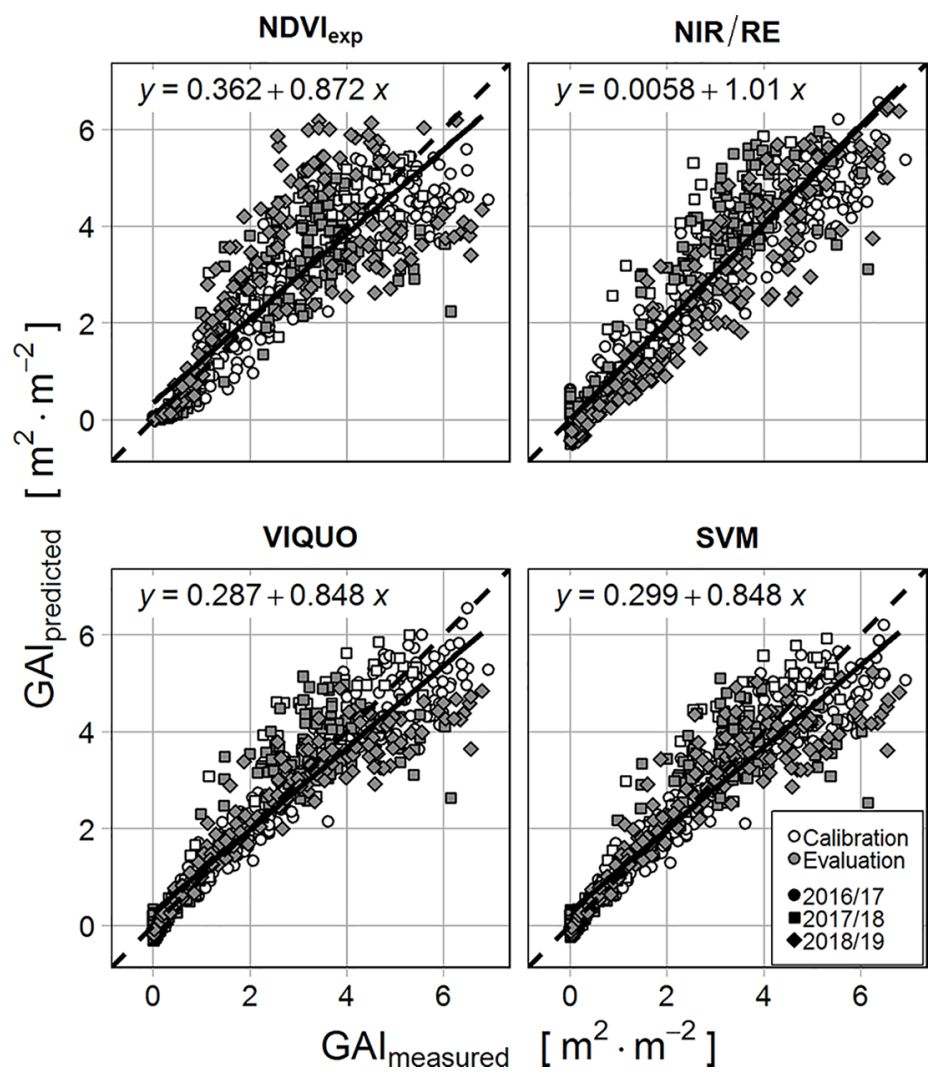

FIGURE 2 | Correlation of measured and predicted GAl for calibration (white) and evaluation dataset (grey) for the different VIs and equation of the linear regression of measured vs. predicted values of the evaluation dataset (different shapes illustrate the three sampling seasons). 
are not met by any of the tested models. These data were obtained during the last sampling date in 2018, after a long period of drought. It is hence probable that they are already affected by senescence, which is not adequate depicted in destructive measurements.

Figure 3 allows a closer view to the topic of varying modelsensitivity through the season: With regard to the MAE, none of the examined VIs has considerable problems in predicting low GAIs ( $>0-<0.25$ \& Dead Plants), with NIR/RE having the highest predictive error $\left(\mathrm{MAE}=0.29 \mathrm{~m}^{2} \mathrm{~m}^{-2}\right)$. Due to the exponential term, the $\mathrm{NDVI}_{\exp }$-model predicts very well in these classes, but it has considerable problems depicting high $G A I$-values, with the highest MAEs in every other GAI-class (Figure 3) and a massive scattering when predicting GAIs $>2$ (Figure 2). SVM and VIQUO perform well at the low values and are very sensitive to medium-range GAIs, with only small differences between the two models. However, a saturation effect is visible at GAIs > 5. In contrast, while the NIR/REmodel is the worst in predicting low GAIs $(0-0.25 \&$ Dead Plants) and only slightly better at medium GAIs $(<2,2-3$ and $3-4)$, it shows the best results when depicting GAIs above four $\left(\mathrm{MAE}=0.81 \mathrm{~m}^{2} \mathrm{~m}^{-2}, \mathrm{rMAE}=16 \%\right)$ and is the only tested approach with no saturation effects at the highest measured $G A I$ values.

For the assessment of cultivar-specific effects, the linear NIR/RE-model was chosen (due to the low number of predictors and the concern to not inflate the number of interactions between cultivars and predictors). No significant difference $(p=0.05)$ between the model with- and without the interaction between reflectance and cultivar information was determined by means of ANOVA and the MAEs of the two models in calibration and evaluation differ only slightly (without interaction: $\mathrm{MAE}_{\text {calibration }}=0.40 \mathrm{~m}^{2} \mathrm{~m}^{-2}, \mathrm{MAE}_{\text {evaluation }}=$
$0.55 \mathrm{~m}^{2} \mathrm{~m}^{-2}$, with interaction: $\mathrm{MAE}_{\text {calibration }}=0.39 \mathrm{~m}^{2} \mathrm{~m}^{-2}$, $\mathrm{MAE}_{\text {evaluation }}=0.54 \mathrm{~m}^{2} \mathrm{~m}^{-2}$ ).

\section{Senescence}

Transforming the SPAD-time series to canopy greenness enables the quantification of the process of senescence (Figure 4). Canopy greenness varies in a large range $\left(\sim 300^{\circ} \mathrm{C} \mathrm{d}, \sim 15 \mathrm{~d}\right)$, due to variation of genotype and soil properties, and enables a robust model evaluation during senescence.

The relationship between measured values of canopy greenness (SPAD-meter) and predicted values (multispectral) by the tested models for GAI-prediction is quite close (Figure 5). Regarding MAE and $\mathrm{R}^{2}$, the model with $\mathrm{NDVI}_{\exp }$ is the worst-performing one (MAE $\left.=0.13 \mathrm{~m}^{2} \mathrm{~m}^{-2} ; \mathrm{R}^{2}=0.91\right)$, followed by VIQUO $\left(\mathrm{MAE}=0.10 \mathrm{~m}^{2} \mathrm{~m}^{-2} ; \mathrm{R}^{2}=0.92\right), \mathrm{NIR} / \mathrm{RE}\left(\mathrm{MAE}=0.10 \mathrm{~m}^{2} \mathrm{~m}^{-2}\right.$; $\left.\mathrm{R}^{2}=0.93\right)$, and SVM (MAE $\left.=0.09 \mathrm{~m}^{2} \mathrm{~m}^{-2} ; \mathrm{R}^{2}=0.94\right)$ as the best performing model. Especially the predictions of the VIQUO- and the SVM-calibration are nearly unbiased.

\section{Suitability for Agricultural Research and Commercial Crop Production}

The application of the selected models to the multispectral data from Trial C in 2017/18 reveals that the different GAI-models provide in part considerably differing results (Figure 6). While the GAI-curves of the NDVI exp $^{-}$, the SVM- and the VIQUO-model are running very smooth and even through the season, the NIR/REmodel has problems during senescence: at two flight dates, the GAI seems to increase again at some plots and at the third-last date negative GAIs are predicted. Apart from these three "problematic" dates with regard to the NIR/RE, the GAI-curves of the SVM, the VIQUO, and the NIR/RE are similar, whereas the $\mathrm{NDVI}_{\text {exp }}$ predicts a faster $G A I$-increase from April to May and an earlier decrease
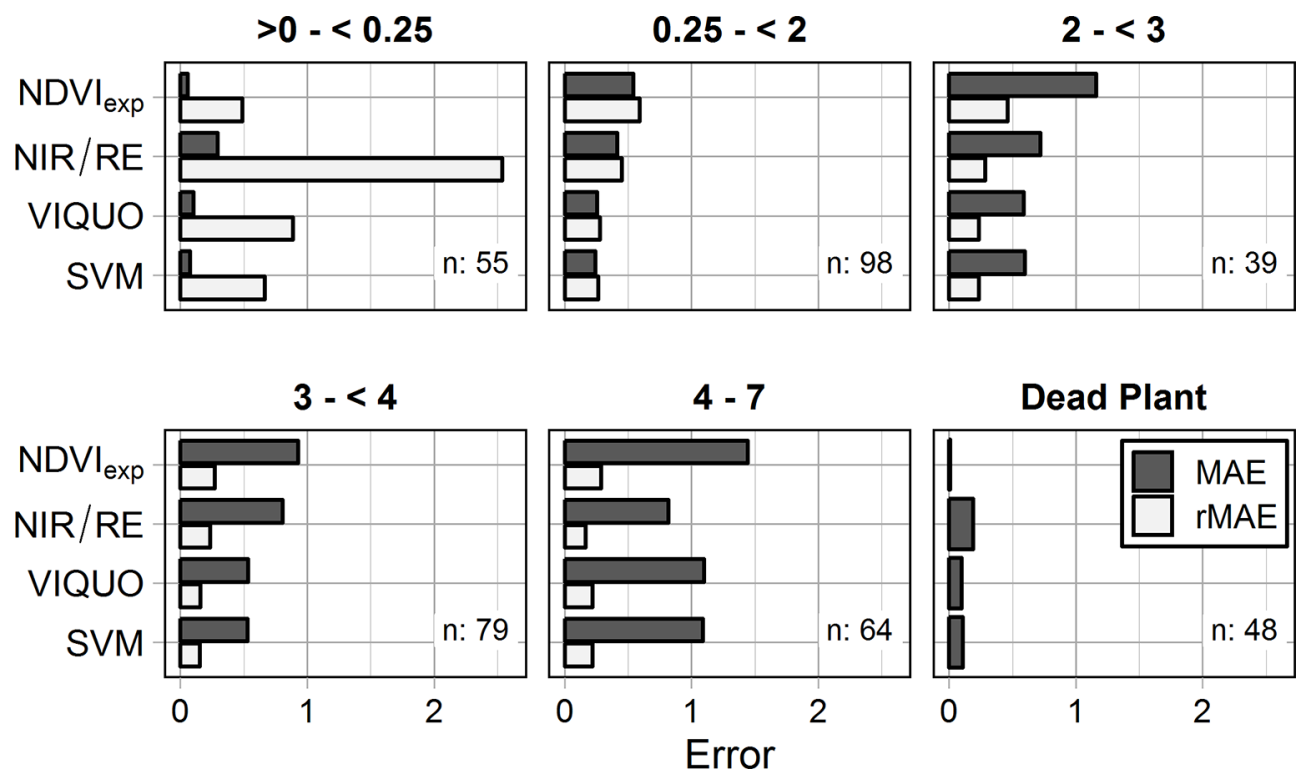

FIGURE 3 | Mean absolute errors (MAE $\left[\mathrm{m}^{2} \mathrm{~m}^{-2}\right]$ ) and relative Mean absolute errors (rMAE [-]) of the different VIs for the evaluation dataset, calculated individually for the different GAl-classes (n: sample size of the considered GAl-class). rMAEs of the class dead plant cannot be calculated due to division by zero. 

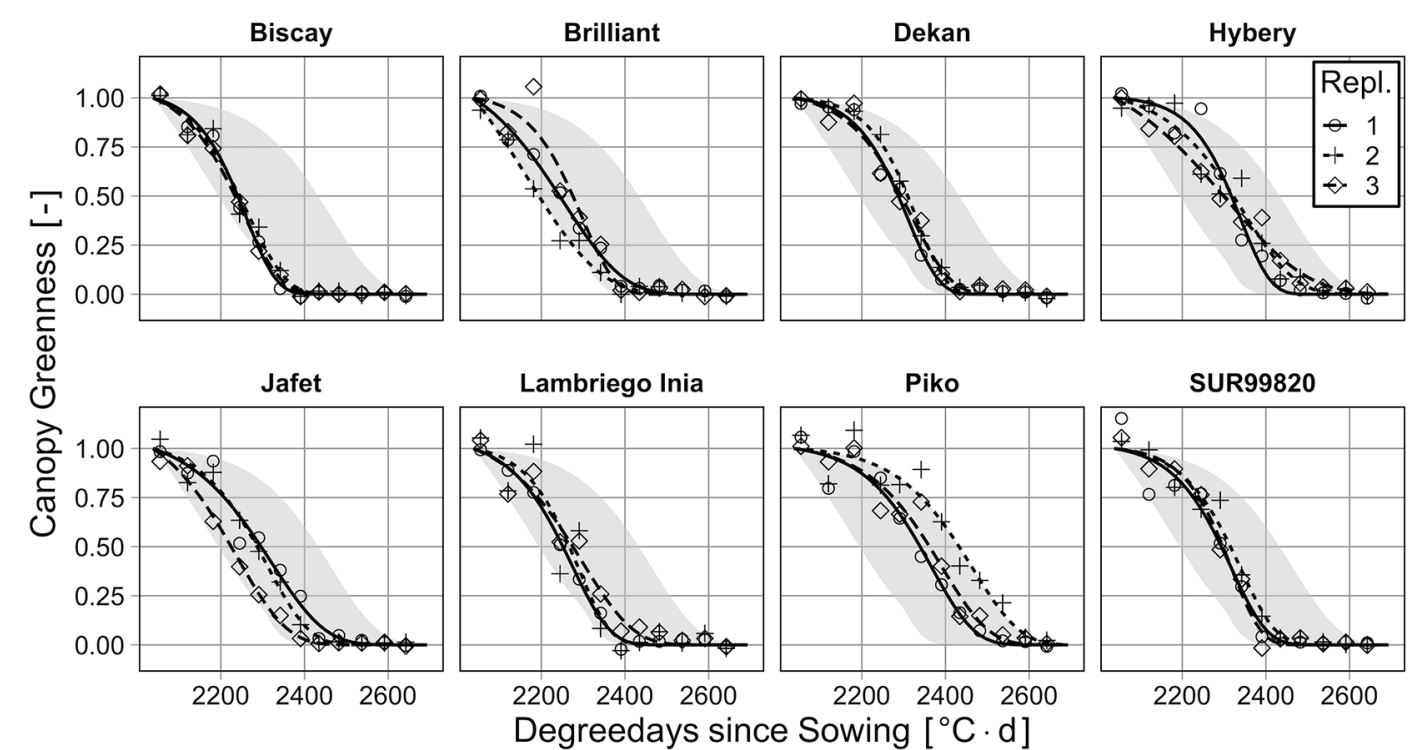

FIGURE 4 | Canopy greenness for eight genotypes, grouped by replication (Repl.), in relation to degree days since sowing. The grey ribbon indicates the range of all genotypes to facilitate their classification.

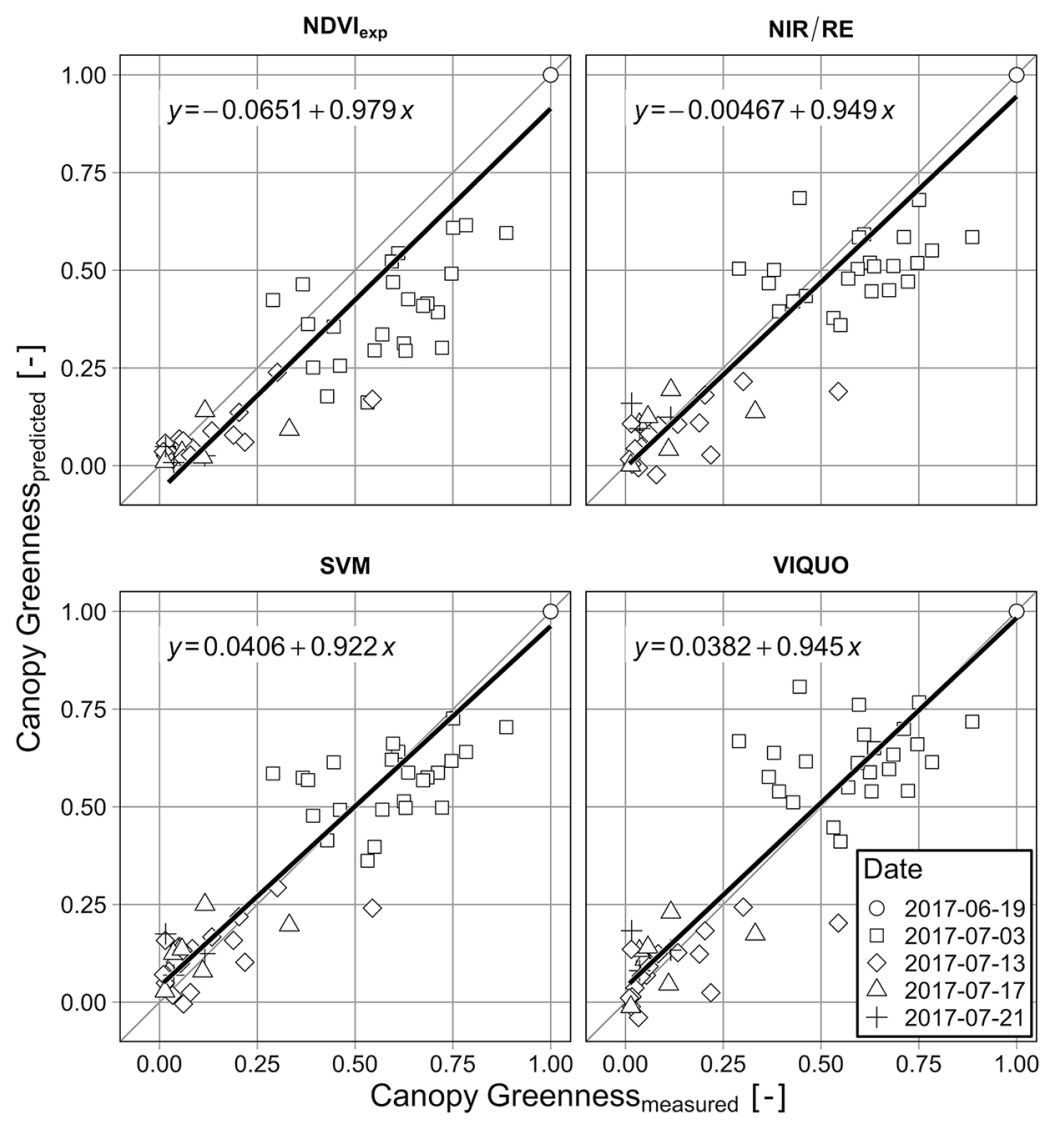

FIGURE 5 | Evaluation of selected GAI-models during the senescence. Data from June 19 is excluded from the calculation of the RMSE because of the selfexplanatory perfect fit. 

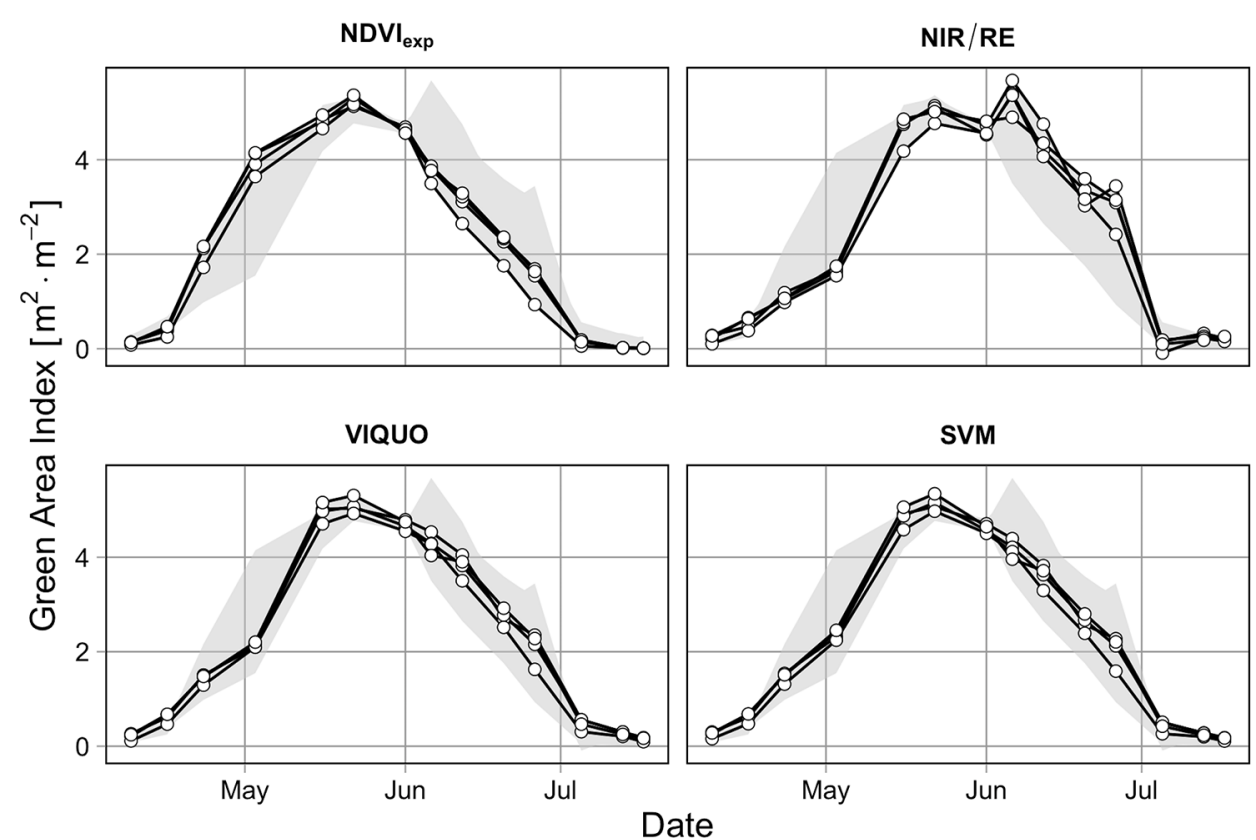

FIGURE 6 | Seasonal course of predicted GAls by different models in the growing season 2017/2018 on four different plots of Trial C (cultivar Solehio, $220 \mathrm{~kg} \mathrm{~N} \mathrm{ha}^{-1}$ ). Grey ribbons indicate the range of all models.

from June to July, reaching a GAI of $0 \mathrm{~m}^{2} \mathrm{~m}^{-2}$ already at the first date in July. This results in notably lower $\mathrm{NDVI}_{\text {exp }}$-estimated green area durations for some plots (Figure 7A). When comparing the green area durations with the final biomasses, the correlation achieved by the $\mathrm{NDVI}_{\text {exp }}$-predictions is nevertheless notably better than those of the NIR/RE-model. This is attributable to the instability of the NIR/RE-model during senescence, as the explained variation decreases notably in this period (Figure 7B). This characteristic of the $\mathrm{R}^{2}$-curve is unique, as the explanatory power of the other GAI-models increases when more data is provided
A

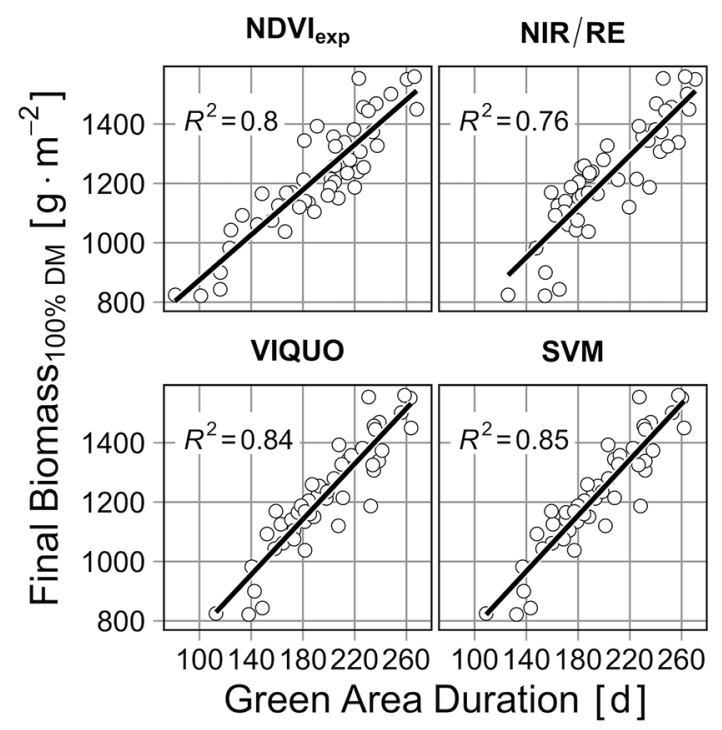

B

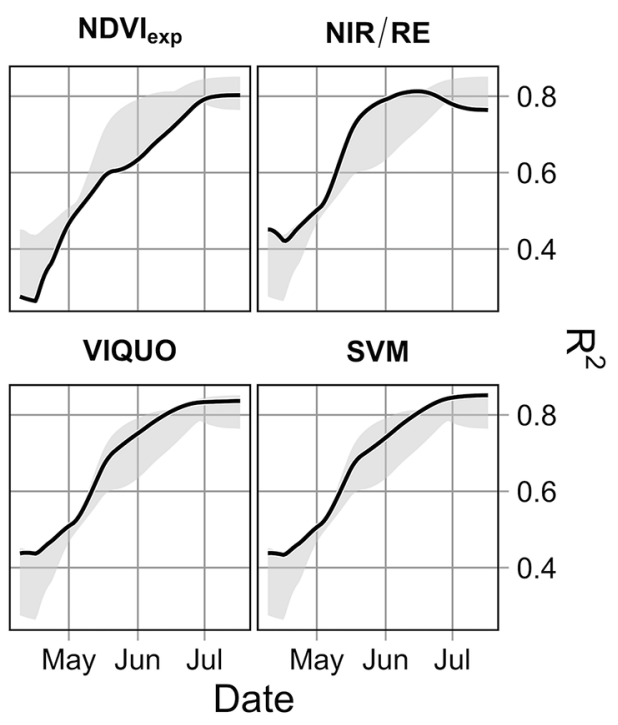

FIGURE 7 | (A) Correlation of total green area duration and final biomass (B) the $\mathrm{R}^{2}$ of the relationship between green area duration (calculated from sowing to date $x$ ) and final biomass, with different models applied for the prediction of GAl. Final date in subfigure B corresponds to subfigure A. 
(Figure 7B). It is only due to this, that the final $\mathrm{R}^{2}$ of the NIR/REpredictions is lower than the one of the $\mathrm{NDVI}_{\text {exp }}$-predictions, as during the rest of the season, the $\mathrm{NDVI}_{\text {exp }}$-based green area duration-predictions have the lowest informative value regarding the final biomass and as the NIR/RE-predictions between May and mid of June are even the best (Figure 7B). It is worth mentioning that in the early May the four GAI-models have approximately the same informative value, explaining about $50 \%$ of the final biomass variation. The $\mathrm{R}^{2}$-curves of VIQUO and SVM increase constantly and almost equally through the season and explain finally the highest proportion of final biomass variation (> 80\%, Figure 7B).

\section{DISCUSSION}

Before discussing different GAI-models or possible areas of application, it is necessary to consider the applicability of the Sequoia camera. Other studies using different UAV-based sensors in general (Duan et al., 2017; Zhou et al., 2017; Condorelli et al., 2018; Kanning et al., 2018), predecessors of the Sequoia sensor (Verger et al., 2014; Haghighattalab et al., 2016; Nebiker et al., 2016) and in particular the Sequoia sensor (Condorelli et al., 2018; Tunca et al., 2018) showed promising results in terms of comparability with ground-based multispectral sensors and their implication to generate information about crop characteristics. Our results match to these findings; the Sequoia camera provides reliable and sufficiently accurate data for crop monitoring purposes on plot level in terms of a scientific context. This should be transferable in the context of commercial crop production as well.

\section{Whole-Season Applicability}

A whole season- and cultivar-transferable approach for GAIprediction is preferable to specific models for several growth stages, concerning simplicity in data processing and communicability, both affecting transferability into practice. In our data, no significant cultivar-specific effect can be identified. When it comes to GAI-prediction, established calibration methods exist until the GAI-maximum is reached. But problems arise when the sensitivity of GAI-models is tested after the start of the senescence, as the accurate identification of the actual GAI is complicated or not possible at all due to the inhomogeneous senescence of the plant organs and the gradual degradation of leaf chlorophyll. Problems in estimating winter wheat GAI during senescence based on multispectral data have also been reported by other studies (Boegh et al., 2002; Haboudane et al., 2004; Lelong et al., 2008; Richter et al., 2012). They assumed that the decreasing performance of their calibrated models originates not from the informative value of the multispectral data but in the validity of the ground truth GAI-measurements. The method introduced in this study, enables the validation of our GAI-models during senescence and hence the confirmation of these considerations. It could thus be shown that the GAI-estimations of the tested models were valid and that the models, being calibrated without any senescence data (except dead plants), can provide reasonable $G A I$-predictions for this part of the season as well.
The quality of the whole-season GAI-predictions was tested further via the calculation of green area duration and the correlation with the final biomass. Hereby, $80 \%$ of the variation in the final biomass is explained by the $\mathrm{NDVI}_{\exp }$-model, which fits to the results of Wiegand et al. (1992) and Tucker et al. (1981) with handheld devices. The new GAI-models VIQUO and SVM explain even more of the observed variance (up to 85\%).

\section{Evaluation of GAI-Models}

The best model to derive GAI-information should provide reliable and precise $G A I$-information as simple as possible. In terms of both, model complexity and communicability, the models can be set in the same order: The application of raw bands is the simplest approach, followed by the traditional twoband ratios. The newly introduced VIQUO-model, based on all four bands the Sequoia camera provides, follows shortly afterwards and the advanced predictive models are for sure the most complex and the most difficult to communicate. Therefore, the central question to be answered is, if the increasing complexity is worth it.

Raw reflection driven models are clearly not sufficient to predict GAI adequately, regardless if they are integrated in an advanced predictive model or not. The increase in MAE from calibration to evaluation indicates instability in the relationship of single bands to GAI between different sampling dates. Problems in predicting crop characteristics with raw reflections under varying irradiance conditions were found by Tucker et al. (1981) and Verger et al. (2014) as well, both demonstrating at the same time that this problem can be solved by using ratios instead.

When applying a two- or more-band approach, the questions of band selection and their combination arise. Many studies have worked on the issue which bands are essential to predict crop characteristics, either based on a priori knowledge about plant reflection characteristics (Baret and Guyot, 1991; Haboudane et al., 2004) or by recording large number of wavelengths with hyperspectral sensors and testing all possible combinations (e.g. Thenkabail et al., 2000; Hansen and Schjoerring, 2003). Based on the finding that already simple ratios (as NIR/RE) provide relatively low MAEs and on the attempt to keep the GAImodels as simple as possible, we restricted our analysis on twoband simple ratios, the combination of all possible simple ratios in the VIQUO and the classical NDVI (with exponential fit), and did not test different band combination approaches. In accordance to the findings of other studies (Serrano et al, 2000; Haboudane et al., 2004; Pinty et al., 2009; Viña et al., 2011) it was shown that the $\mathrm{NDVI}_{\exp }$ is insensitive in dense canopies (here: $G A I>2 \mathrm{~m}^{2} \mathrm{~m}^{-2}$ ). The NIR/RE, as best Simple Ratio, is superior in predicting high GAIs. This result is in accordance with many studies (e.g. Delegido et al.,2013; Zhou et al., 2017) that the RE-band provides information even at high canopy densities. However, the model performs inaccurately at low GAIs and the NIR/RE-calculated GAI-curves are not stable through the season. The latter could be a result of both, of lower sensitivity of NIR/RE in the phase of senescence or of technical problems of the RE-band (the RE-band is the narrowest of the used bands, which could result in instabilities in the measurements, for example at low irradiation). 
The VIQUO- and the SVM-model can compensate the temporarily low sensitivity of the RE-band and provide stable GAI-predictions over the whole season. A stabilization of cropcharacteristic estimations with regard to differing irradiance conditions by adding additional bands to the traditional twoband approach has been reported by Mistele and Schmidhalter (2010) as well. Other studies describe a decreasing saturation effect and an increase of sensitivity obtained through additional bands (Haboudane et al., 2004; Delegido et al., 2013). Haboudane et al. (2004) increased the sensitivity of their model to GAI-values $>4 \mathrm{~m}^{2} \mathrm{~m}^{-2}$ by adding a green-band to their NIR-Red-model and achieved a whole season RMSE of $0.79-1.28 \mathrm{~m}^{2} \mathrm{~m}^{-2}$. In our case, the VIQUO, including additionally the RE-band, is sensitive to $G A I$-values $\leq 5 \mathrm{~m}^{2} \mathrm{~m}^{-2}$ and produces even more accurate predictions $\left(\mathrm{RMSE}_{\text {evaluation }}=0.72 \mathrm{~m}^{2} \mathrm{~m}^{-2}\right)$. Due to a very high fraction of intercepted radiation at $G A I$-values $\geq 5$, we hold that sensitivity at rather low values is more important for the model-selection. For different requirements, the NIR/RE-model with its high sensitivity at high $G A I$-values might be the adequate approach.

The advanced predictive models are able to produce lower RMSEs than the VI-models, with the SVM even surpassing the VIQUO $\left(\right.$ RMSE $\left._{\text {evaluation }}=0.71 \mathrm{~m}^{2} \mathrm{~m}^{-2}\right)$. This improvement in GAIprediction is in accordance to the findings of Hansen and Schjoerring (2003), but notably lower than that of Verrelst et al. (2015), where the advanced predictive model reduced the RMSE by nearly $30 \%$. This could be due to their data set, as a simultaneous consideration of different crop types might require more complex model methods, or due to their evaluation approach, as they used a cross-validation instead of an independent dataset, increasing the probability of overparameterization. While there are no indications that the here presented SVM-model is overparametrized (same decrease in predictive power from calibration to evaluation than the testes Simple Ratio-models), it has the same saturation effect for $G A I$-values $>5$ as the VIQUO. Considering the sensitivity in the different GAI-classes, the SVM is predicting mostly, but not in every case, GAI more precise than the VIQUO. The GAI-curves estimated with these two different models are nearly the same and the correlation of green area duration to final biomass of the SVMmodel is consequently not notably better. On this base we consider the higher complexity of the advanced predictive model as not justified.

\section{Transferability of the GAI-Calibration}

Lastly, besides the validity through the whole season for different cultivars, the applicability of the GAI-calibration across seasons should be considered. In general, the transferability of purely statistic-based approaches, as the calibration here presented, might be regarded as problematic. Additionally, the use of destructive GAI-data restricts the size of the data set to the affordable workload and the local conditions of the respective study site (e.g. number of seasons, plots, cultivars, nitrogen levels). A concept to overcome these problems is the use of radiative transfer models, such as PROSAIL, to generate reflectance- and LAI-data sets for the sensor of interest (Richter et al., 2010; Verger et al., 2014). However, this approach relies on the estimation of several crop parameters (e.g. average leaf angle, dry matter content, leaf mesophyll parameter). These parameters may vary in plot trials, for example due to different cultivars and fertilization levels (as exemplarily shown above for two cultivars), and probably also on farm sites with heterogeneous crop growth. Furthermore problematic may be to depict the sensitivity of the raw bands to illumination conditions during image acquisition when generating artificially reflectance data (Verger et al., 2014) and the saturation effect when considering high GAIs (Richter et al., 2010; Verger et al., 2014). These effects could be examined closer in further investigations, using our data set as basis for evaluation. However, taking into account these restrictions of physically based calibration approaches, statistically-based approaches can probably be considered at least of equal standing and have shown to be stable over multiple seasons and many different measurement dates in the presented data set.

\section{CONCLUSION}

The Sequoia multispectral camera was identified as an adequate instrument for multispectral data acquisition for crop monitoring.

Different models for GAI-estimation were presented and evaluated. For this purpose, a new approach for evaluating GAI-models during senescence was introduced and tested successfully.

Only two of the tested GAI-models can be considered as reliable and sufficiently accurate for whole-season GAIprediction; the newly developed four-band VI-approach VIQUO and the advanced predictive model SVM. Both models use all four spectral bands provided by the Sequoia camera. The two-band approaches are outperformed in terms of stability and sensitivity. Only if especially sensitivity at high GAI-values is of major importance, the alternative use of the NIR/RE-model should be considered.

The VIQUO-model is recommended as best model to estimate winter wheat $G A I$, as it provides a high precision in $G A I$-prediction and is still relatively simple, thus easier to communicate and to apply than the SVM.

The strong correlation between green area duration (derived from $G A I$-predictions) and the final biomass demonstrates the high potential of the used system (in combination with appropriate calibration) for the application in agriculture research and precision farming.

\section{DATA AVAILABILITY STATEMENT}

The datasets generated for this study are available on request to the corresponding author.

\section{AUTHOR CONTRIBUTIONS}

JB was coordinating author and in cooperation with TR conducting the major part of measurements and writing process. RE provided sampling and base analysis for the part 
about senescence during his bachelor thesis. HK was supervisor of the whole process, defined central ideas of the article and corrected the manuscript

\section{FUNDING}

This work was supported by the foundation SchleswigHolsteinische Landschaft and the Federal Ministry of Education and Research (BMBF) (grant number: 031A354D). Publication fees were supported by Land Schleswig-Holstein within the funding program Open Access Publikationsfonds.

\section{REFERENCES}

Allen, J., Amato, G., Balda, M., Bar, F., Bauer, J., Baumgartner, M., et al. (2011). UAS Yearbook - The Global Perspective 2011/2012. (Paris, France: Blyenburgh \& Co).

Baret, F., and Guyot, G. (1991). Potentials and limits of vegetation indices for LAI and APAR assessment. Remote Sens. Environ. 35 (2-3), 161-173. doi: 10.1016/ 0034-4257(91)90009-U

Bartholome, E. (1988). Radiometric measurements and crop yield forecasting Some observations over millet and sorghum experimental plots in Mali. Int. J. Remote Sens. 9 (10-11), 1539-1552. doi: 10.1080/01431168808954959

Beard, R., Kingston, D., McLain, T. W., and Nelson, D. (2006). Decentralized cooperative aerial surveillance using fixed-wing miniature UAVs. Proc. IEEE 94 (7), 722-738. doi: 10.1109/JPROC.2006.876930

Berni, J. A., Zarco-Tejada, P. J., Suárez Barranco, M. D., and Fereres Castiel, E. (2009). Thermal and narrow-band multispectral remote sensing for vegetation monitoring from an unmanned aerial vehicle. IEEE Trans. Geosci. Remote Sens. 47, 722-738. doi: 10.1109/TGRS.2008.2010457

Boegh, E., Soegaard, H., Broge, N., Hasager, C. B., Jensen, N. O., Schelde, K., et al. (2002). Airborne multispectral data for quantifying leaf area index, nitrogen concentration, and photosynthetic efficiency in agriculture. Remote Sens. Environ. 81 (2-3), 179-193. doi: 10.1016/S0034-4257(01)00342-X

Broge, N. H., and Mortensen, J. V. (2002). Deriving green crop area index and canopy chlorophyll density of winter wheat from spectral reflectance data. Remote Sens. Environ. 81 (1), 45-57. doi: 10.1016/S0034-4257(01)00332-7

Burges, C. J. (1998). A tutorial on support vector machines for pattern recognition. Data Min. Knowl. Discovery 2 (2), 121-167. doi: 10.1023/A:1009715923555

Chen, J. M., and Cihlar, J. (1996). Retrieving leaf area index for boreal conifer forests using Landsat TM images. Remote Sens. Environ. 55 (2), 153-162. doi: 10.1016/0034-4257(95)00195-6

Condorelli, G. E., Maccaferri, M., Newcomb, M., Andrade-Sanchez, P., White, J. W., French, A. N., et al. (2018). Comparative aerial and ground based high throughput phenotyping for the genetic dissection of NDVI as a proxy for drought adaptive traits in durum wheat. Front. Plant. Sci. 9, 893. doi: 10.3389/ fpls.2018.01885

Delegido, J., Verrelst, J., Meza, C. M., Rivera, J. P., Alonso, L., and Moreno, J. (2013). A red-edge spectral index for remote sensing estimation of green LAI over agroecosystems. Eur. J. Agron. 46, 42-52. doi: 10.1016/j.eja.2012.12.001

Deutscher Wetterdienst (2013). Wetter und Klima - Deutscher Wetterdienst Startseite. http://dwd.de [Accessed February 7, 2013].

Duan, T., Chapman, S. C., Guo, Y., and Zheng, B. (2017). Dynamic monitoring of NDVI in wheat agronomy and breeding trials using an unmanned aerial vehicle. Field Crops Res. 210, 71-80. doi: 10.1016/j.fcr.2017.05.025

Gitelson, A. A., Viña, A., Arkebauer, T. J., Rundquist, D. C., Keydan, G., and Leavitt, B. (2003). Remote estimation of leaf area index and green leaf biomass in maize canopies. Geophys. Res. Lett. 30 (5), 1248. doi: 10.1029/2002GL016450

Höskuldsson, A. (1988). PLS regression methods. J. Chemom. 2 (3), 211-228. doi: $10.1002 / \mathrm{cem} .1180020306$

Haboudane, D., Miller, J. R., Pattey, E., Zarco-Tejada, P. J., and Strachan, I. B. (2004). Hyperspectral vegetation indices and novel algorithms for predicting green LAI of crop canopies: modeling and validation in the context of precision

\section{ACKNOWLEDGMENTS}

The authors thank Ms. Kiesow, Ms. Schulz, Ms. Weise, and Ms. Ziermann for their dedicated field work and the land survey office of Schleswig-Holstein for the provision of RINEX-files.

\section{SUPPLEMENTARY MATERIAL}

The Supplementary Material for this article can be found online at: https://www.frontiersin.org/articles/10.3389/fpls.2019. 01798/full\#supplementary-material

agriculture. Remote Sens. Environ. 90 (3), 337-352. doi: 10.1016/j.rse.2003. 12.013

Haghighattalab, A., Pérez, L. G., Mondal, S., Singh, D., Schinstock, D., Rutkoski, J., et al. (2016). Application of unmanned aerial systems for high throughput phenotyping of large wheat breeding nurseries. Plant. Methods 12 (1), 35. doi: 10.1186/s13007-016-0134-6

Hansen, P. M., and Schjoerring, J. K. (2003). Reflectance measurement of canopy biomass and nitrogen status in wheat crops using normalized difference vegetation indices and partial least squares regression. Remote Sens. Environ. 86 (4), 542-553. doi: 10.1016/S0034-4257(03)00131-7

Kanning, M., Kühling, I., Trautz, D., and Jarmer, T. (2018). High-resolution UAVbased hyperspectral imagery for LAI and chlorophyll estimations from wheat for yield prediction. Remote Sens. 10 (12), 2000. doi: 10.3390/rs10122000

Karatzoglou, A., Smola, A., Hornik, K., and Zeileis, A. (2004). kernlab-an S4 package for kernel methods in R. J. Stat. Software 11 (9), 1-20. doi: 10.18637/ jss.v011.i09

Kuhn, M. (2017). caret: Classification and Regression Training

Lancashire, P. D., Bleiholder, H., Boom, T. V. D., Langelüddeke, P., Stauss, R., Weber, E., et al. (1991). A uniform decimal code for growth stages of crops and weeds. Ann. Appl. Biol. 119 (3), 561-601. doi: 10.1111/j.1744-7348.1991.tb04895.x

Lelong, C. C., Burger, P., Jubelin, G., Roux, B., Labbé, S., and Baret, F. (2008). Assessment of unmanned aerial vehicles imagery for quantitative monitoring of wheat crop in small plots. Sensors 8 (5), 3557-3585. doi: 10.3390/s8053557

Li, F., Miao, Y., Hennig, S. D., Gnyp, M. L., Chen, X., Jia, L., et al. (2010). Evaluating hyperspectral vegetation indices for estimating nitrogen concentration of winter wheat at different growth stages. Precis. Agric. 11 (4), 335-357. doi: 10.1007/s11119-010-9165-6

Ling, Q., Huang, W., and Jarvis, P. (2011). Use of a SPAD-502 meter to measure leaf chlorophyll concentration in Arabidopsis thaliana. Photosynth. Res. 107 (2), 209-214. doi: 10.1007/s11120-010-9606-0

Majumdar, J., Duggal, A., and Narayanan, K. G. (2001). Image exploitation-A forefront area for UAV application. Defence Sci. J. 51 (3), 239. doi: 10.14429/ dsj.51.2235

Markwell, J., Osterman, J. C., and Mitchell, J. L. (1995). Calibration of the Minolta SPAD-502 leaf chlorophyll meter. Photosynth. Res. 46 (3), 467-472. doi: 10.1007/BF00032301

Mevik, B.-H., Wehrens, R., and Hovde Liland, K. (2016). pls: Partial Least Squares and Principal Component Regression.

Milborrow, S. (2017). Earth: Multivariate Adaptive Regression Splines.

Mistele, B., and Schmidhalter, U. (2010). Tractor-based quadrilateral spectral reflectance measurements to detect biomass and total aerial nitrogen in winter wheat. Agron. J. 102 (2), 499-506. doi: 10.2134/agronj2009.0282

Myneni, R. B., Ramakrishna, R., Nemani, R., and Running, S. W. (1997). Estimation of global leaf area index and absorbed PAR using radiative transfer models. IEEE Trans. Geosci. Remote Sens. 35 (6), 1380-1393. doi: $10.1109 / 36.649788$

Nebiker, S., Lack, N., Abächerli, M., and Läderach, S. (2016). Light-Weight multispectral UAV sensors and their capabilities for predicting grain yield and detecting plant diseases. Int. Arch. Photogramm. Remote Sens. Spat. Inf. Sci. 41, 963-970. doi: 10.5194/isprsarchives-XLI-B1-963-2016 
Ni, J., Yao, L., Zhang, J., Cao, W., Zhu, Y., and Tai, X. (2017). Development of an unmanned aerial vehicle-borne crop-growth monitoring system. Sensors 17 (3), 502. doi: 10.3390/s17030502

Pinter, P. J. Jr., Jackson, R. D., Idso, S. B., and Reginato, R. J. (1981). Multidate spectral reflectance as predictors of yield in water stressed wheat and barley. Int. J. Remote Sens. 2 (1), 43-48. doi: 10.1080/014311 68108948339

Pinty, B., Lavergne, T., Widlowski, J. L., Gobron, N., and Verstraete, M. M. (2009). On the need to observe vegetation canopies in the near-infrared to estimate visible light absorption. Remote Sens. Environ. 113 (1), 10-23. doi: 10.1016/ j.rse.2008.08.017

Puri, V., Nayyar, A., and Raja, L. (2017). Agriculture drones: a modern breakthrough in precision agriculture. J. Stat. Manage. Syst. 20 (4), 507-518. doi: 10.1080/09720510.2017.1395171

QGIS Development Team (2018). QGIS Geographic Information System. Open Source Geospatial Foundation Project. http://qgis.osgeo.org [Accessed January $31,3018]$.

R Core Team (2017). R: A Language and Environment for Statistical Computing (Vienna, Austria: R Foundation for Statistical Computing).

Raparelli, E., and Bajocco, S. (2019). A bibliometric analysis on the use of unmanned aerial vehicles in agricultural and forestry studies. Int. J. Remote Sens., 40, 9070-9083. doi: 10.1080/01431161.2019.1569793

Rasmussen, M. S. (1992). Assessment of millet yields and production in northern Burkina Faso using integrated NDVI from the AVHRR. Int. J. Remote Sens. 13 (18), 3431-3442. doi: 10.1080/01431169208904132

Richter, K., Atzberger, C., Vuolo, F., and D’Urso, G. (2010). Evaluation of sentinel2 spectral sampling for radiative transfer model based LAI estimation of wheat, sugar beet, and maize. IEEE J. Sel. Top. Appl. Earth Obs. Remote Sens. 4 (2), 458-464. doi: 10.1109/JSTARS.2010.2091492

Richter, K., Hank, T. B., Vuolo, F., Mauser, W., and D'Urso, G. (2012). Optimal exploitation of the Sentinel-2 spectral capabilities for crop leaf area index mapping. Remote Sens. Environ. 4 (3), 561-582. doi: 10.3390/rs4030561

Ridgeway, G. (2017). gbm: Generalized Boosted Regression Models.

Rouse, J. W.Jr., Haas, R. H., Schell, J. A., and Deering, D. W. (1974). Monitoring vegetation systems in the great plains with ERTS. Proc. Third ERTS Symp., 309-317.

Salamí, E., Barrado, C., and Pastor, E. (2014). UAV flight experiments applied to the remote sensing of vegetated areas. Remote Sens. 6 (11), 11051-11081. doi: $10.3390 /$ rs61111051

Serrano, L., Filella, I., and Penuelas, J. (2000). Remote sensing of biomass and yield of winter wheat under different nitrogen supplies. Crop Sci. 40 (3), 723-731. doi: 10.2135/cropsci2000.403723x

Thenkabail, P. S., Smith, R. B., and De Pauw, E. (2000). Hyperspectral vegetation indices and their relationships with agricultural crop characteristics. Remote Sens. Environ. 71 (2), 158-182. doi: 10.1016/S0034-4257(99)00067-X

Tsouros, D. C., Bibi, S., and Sarigiannidis, P. G. (2019). A review on UAV-based applications for Precision Agriculture. Information 10 (11), 349. doi: 10.3390/ info10110349
Tucker, C. J., Holben, B. N., Elgin, J. H.Jr., and McMurtrey, J. E. III (1981). Remote sensing of total dry-matter accumulation in winter wheat. Remote Sens. Environ. 11, 171-189. doi: 10.1016/0034-4257(81)90018-3

Tunca, E., Köksal, E. S., Çetin, S., Ekiz, N. M., and Balde, H. (2018). Yield and leaf area index estimations for sunflower plants using unmanned aerial vehicle images. Environ. Monit. Assess. 190 (11), 682. doi: 10.1007/s10661-018-7064-x

Uddling, J., Gelang-Alfredsson, J., Piikki, K., and Pleijel, H. (2007). Evaluating the relationship between leaf chlorophyll concentration and SPAD-502 chlorophyll meter readings. Photosynth. Res. 91 (1), 37-46. doi: 10.1007/ s11120-006-9077-5

Verger, A., Vigneau, N., Chéron, C., Gilliot, J. M., Comar, A., and Baret, F. (2014). Green area index from an unmanned aerial system over wheat and rapeseed crops. Remote Sens. Environ. 152, 654-664. doi: 10.1016/j.rse.2014.06.006

Verrelst, J., Camps-Valls, G., Muñoz-Marí, J., Rivera, J. P., Veroustraete, F., Clevers, J. G., et al. (2015). Optical remote sensing and the retrieval of terrestrial vegetation bio-geophysical properties-a review. ISPRS J. Photogramm. Remote Sens. 108, 273-290. doi: 10.1016/j.isprsjprs.2015.05.005

Viña, A., Gitelson, A. A., Nguy-Robertson, A. L., and Peng, Y. (2011). Comparison of different vegetation indices for the remote assessment of green leaf area index of crops. Remote Sens. Environ. 115 (12), 3468-3478. doi: 10.1016/ j.rse.2011.08.010

Watson, D. J., Thorne, G. N., and French, S. A. W. (1963). Analysis of growth and yield of winter and spring wheats. Ann. Bot. 27 (1), 1-22. doi: 10.1093/ oxfordjournals.aob.a083825

Weiss, M., Jacob, F., and Duveiller, G. (2020). Remote sensing for agricultural applications: a meta-review. Remote Sens. Environ. 236, 111402. doi: 10.1016/ j.rse.2019.111402

Wiegand, C. L., Maas, S. J., Aase, J. K., Hatfield, J. L., Pinter, P. J.Jr., Jackson, R. D., et al. (1992). Multisite analyses of spectral-biophysical data for wheat. Remote Sens. Environ. 42 (1), 1-21. doi: 10.1016/0034-4257(92)90064-Q

Zecha, C. W., Link, J., and Claupein, W. (2013). Mobile sensor platforms: Categorisation and research applications in precision farming. J. Sens. Sens. Syst. 2 (1), 51-72. doi: 10.5194/jsss-2-51-2013

Zhou, X., Zheng, H. B., Xu, X. Q., He, J. Y., Ge, X. K., Yao, X., et al. (2017). Predicting grain yield in rice using multi-temporal vegetation indices from UAV-based multispectral and digital imagery. ISPRS J. Photogramm. Remote Sens. 130, 246-255. doi: 10.1016/j.isprsjprs.2017.05.003

Conflict of Interest: The authors declare that the research was conducted in the absence of any commercial or financial relationships that could be construed as a potential conflict of interest.

Copyright (c) 2020 Bukowiecki, Rose, Ehlers and Kage. This is an open-access article distributed under the terms of the Creative Commons Attribution License (CC BY). The use, distribution or reproduction in other forums is permitted, provided the original author(s) and the copyright owner(s) are credited and that the original publication in this journal is cited, in accordance with accepted academic practice. No use, distribution or reproduction is permitted which does not comply with these terms. 